\title{
Measuring the Horizon: Objectivity, Subjectivity and the Dignity of Human Personal Identity
}

\author{
Francis J. Ambrosio ${ }^{1,2}$, Elisabetta Lanzilao ${ }^{2}$ \\ ${ }^{1}$ Department of Philosophy, Georgetown University, Washington, DC, USA \\ ${ }^{2}$ Department of Liberal Studies, Georgetown University, Washington, DC, USA \\ Email: ambrosif@georgetown.edu.el640@georgetown.edu
}

Received October $7^{\text {th }}$, 2013; revised November $7^{\text {th }}$, 2013; accepted November $14^{\text {th }}, 2013$

\begin{abstract}
Copyright @ 2013 Francis J. Ambrosio, Elisabetta Lanzilao. This is an open access article distributed under the Creative Commons Attribution License, which permits unrestricted use, distribution, and reproduction in any medium, provided the original work is properly cited.
\end{abstract}

\begin{abstract}
It is argued in what follows that "culture warfare" is symptomatic of an imminent threat to the continued sustainability of human culture as a whole. The nature of this threat can be characterized as trauma induced paralysis of the human cultural imagination, without which cooperative adaptation to potential credible dangers of self-induced species or even planetary life extinction is impossible. The structure of this paradoxical "possible impossibility" as the destiny of humanity is examined here within the context of an interpretive framework which is broadly characterized as "cultural genetics". On the basis of a schematic and preliminary outline of that framework, a suggestion is made regarding the direction in which hope of avoiding that destiny might be sought.
\end{abstract}

Keywords: Quantity; Quality; Objectivity; Subjectivity; Worldview; Culture-War; Hero; Saint; Secular Saint; Cartesian Anxiety; Meaningful; Freedom; Responsibility

\section{The Rise of Quantitation}

The pioneering idea that the act of "measuring" discloses the possibility for the conjunction of the two realities of "Quantity" and "Quality", otherwise indifferent to each other, was firstly launched by G. W. F. Hegel. In his monumental Science of Logic (Hegel, 1812-1816), he defines "measure" as "the immanent quantitative relationship of two qualities to each other", where Quantity is conceptualized as "pure Being” in a sense of a character external to being, indifferent to it and superseding it, and Quality as the "character identical with Being" corresponding to its very essential substance. As Hegel maintains, measuring starts with the objective process of determination, and moves eventually to include the subjective component of human interpretation. Hegel's synthetic ambition, however, has not been widely favored in the historical evolution of cultural traditions since he wrote, wherein Quantity and Quality continued to be dominantly regarded as separate "absolute" concepts, functioning as matrices of alternative, mostly competing paradigms, each orienting itself along lines consistent with its tacit core assumptions about reality as a whole. The systematization of Quantity as an aspect of Nature had been conceptually inaugurated by Aristotle and articulated mathematically with the ultimate purpose of codifying the experiential observation of physical science and translating it into a measurable and countable, and thus intelligible and comparable data set. With the advent of the enlightenment, the opportunity that this notion opened up for an objectively standardized quantifiability of the objects of inquiry of the physical sciences quickly came to be celebrated as the primary vehicle for the advancement not only of science and the evolution of human knowledge through scientific method, but also as the primary means of progress for society as a whole.

Additionally, Quantity and quantifiability gained further traction with the rise of Marxist theory of Historical Materialism and the unquestionable centrality which accorded to "social capital" thereby making the measurement of social forces and the covert effects of alienation and the dominance of class structures accessible to methods of empirical investigation. Far from being an antagonist in this development, the rise of economic theory as a social science in support of capitalism itself served to buttress the centrality of quantitation as a vehicle of objective analysis that could be applied directly to questions formerly regarded as the sole province of qualitative standards. Finally, the speed of technological advances and the pervasiveness of their application to an increasingly broad range of domains also rely, today at the time of the first technological revolution, on the same notion of quantifiability and standardization of data, fully subsumed as the premise of social sciences' methodology of analysis as well.

Even so a broadly and incompletely sketched portrait of the historical trajectory of the rise of Quantity as the standard measure of the objectivity of cultural norms of human wellbeing confirms that the wide spread common sense prejudice in favor of Quantity over Quality, together with the opposite and almost equal counter-prejudice, are both historically and culturally grounded in the widely acknowledged reliability of standardized data as the methodological prerequisite for any kind of deliberation involving rational decision making. From policy making to business strategy among the most blatant cases, Utilitarianism has become established as a well-respected decision algorithm. In a utilitarian approach, the value of an object or action is estimated in terms of its utility, where the utility here considered is measured in terms of the "greatest happiness 
for the greatest number”. Utilitarianism openly demonstrates that Quality implications inevitably arise in the realm of quantification. Nevertheless, the examples of the unsustainable excesses of contemporary fiscal and monetary policies, as well as the progressive degradation of the natural environment, clearly demonstrate that the adequacy of adopting quantitation as the regnant decision-making paradigm to comprehensively assess all the factors determining the quality of human experience is highly arguable. Rarely are qualitative differences in terms of human values adequately appraised by quantitation, and even when such quantity valuation is applied to encompass quality parameters, the relevance of the latter is inevitably reduced to the narrow scope allowed by statistical analyses and their consequent objectification.

The strategic approach offered here to this apparent dilemma proposes a transposition of the horizon against which the dilemma is profiled, rather than championing yet another rabbit-out-of-the hat solution to the problem. Indeed the primary point of what follows could be adequately, albeit cryptically, summarized as the need to recognize that the apparent dichotomy of Quantity and Quality arises precisely from a failure to recognize the horizon which in fact they necessarily share, and as a result, to become trapped in a type of reductive fallacy that portrays a structural necessity of human experience, its mediation in and as language, as a problem could be resolved by the illusion of a preferential choice. More specifically, the proposal made here is that the characteristics and inter-relations of the notions of Quantity and Quality can be more effectively explored and understood when they are situated within the more inclusive horizons of Objectivity and Subjectivity respectively, and the characteristics of which we can outline starting from a contemporary example of long standing traditions of cultural confrontation between equally self-referential and legitimate truth claim appeal to highly polarized and irreconcilable horizons of meaning.

\section{Paralyzing Culture-Warfare}

In The God Delusion (Dawkins, 2006), Richard Dawkins makes a sustained and urgent case that religion is the instigator of myriad social ills and the cause of widespread harm to human beings. Dawkins' diagnosis of the cancerous pathology of religion is that it originates in one disastrous mutation in the human cultural genome, the emergence of the "faith" meme, which predisposes its carriers to take as real that for which no objective evidence can be adduced, but which nonetheless is perceived as offering some significant survival advantage in the form of the promise of salvation from death.

Effectively Dawkins is arguing that modern science has progressively demonstrated that rationality should be recognized as having the authority to rule out belief and value claims which cannot, at least in principle, be subjected to rigorous standards of empirical objectivity and fully explained within the limits of scientific naturalism. As an ethologist and evolutionary biologist, Dawkins recognizes the reality and significance of human subjectivity as the source of the rich coloration of human experience with the hues and tones of meaning that ultimately makes life worth living. Nonetheless, he believes that unless subjectivity is disciplined and bounded by the limits of objective inquiry, it risks deluding and betraying human beings into destructive fantasies of the type that have historically thrived and proven so virulently contagious within the context of religious culture.
To put Dawkins fully into perspective, however, requires extending the horizon here by introducing one of his more formidable adversaries in the war of worldviews, Francis Collins, author of The Language of God (Collins, 2006). At first glance, Collins offers an interesting counterpoint to Dawkins, because his stature of Director of the Human Genome Project is arguably comparable to Dawkins in the field of genetics which they share. Against this backdrop of unquestionable expertise in the same scientific field, one cannot help but be arrested at least momentarily by the fact that Dawkins champions atheism and Collins, with equal fervor, champions theistic religion.

As the father of the BioLogos ("Life through Word") theory, Collins claims that evolution and biological complexity proceeded by Darwinian natural selection after a creationist principium ascribable to a supernatural Creator who astonishingly tuned the physical parameters for life. Interestingly, however, he then resorts to the dignity accruing to the human person, the existence of a universal moral law and the spontaneous search for God invariably recurring in all cultural traditions as the objective evidence for his claim of privileged authority faith claims. He maintains that the acknowledgment of human dignity cannot be adequately accounted for exclusively in naturalistic terms, i.e. as the product of any process of evolutionary natural selection. The genuine universality of an absolute ${ }^{1}$ inviolability of human dignity requires positing a transcendent reality of the sort that theistic religion generally affirms God to be.

Profiled against this polarity of belief regarding the existence of God, what emerges as even more striking upon reflection is that the line of argumentation which each protagonist deploys reveals a way of thinking that is even more consequential, humanly and intellectually, than the polar opposition of their stands on religion. Both of them are ultimately reductionists, though of different kinds.

With regard to truth and value claims concerning fundamental questions of reality as a whole and especially of human existence, a reductionist is one who holds that, despite the legitimate and productive diversity of "perspectives" that might be taken on the broad spectrum of these human questions, there is nonetheless one perspective which in the end "trumps" any other perspective with regard to its authority finally to adjudicate such claims. For Dawkins, the perspective which provides the criteria against which all other questions can ultimately be judged is the objectivity of the natural sciences. The privileged perspective to which Collins has final resort is what he identifies as the objectivity of the universal moral law, not in the form of any specific code of morality but in the more general sense of innateawareness of right and wrong, a sort of "golden rule" which is reflected across the spectrum of almost all religions and cultural value systems, from the Code of Hammurabi to the United Nations Universal Declaration of Human Rights.

The Dawkins-Collins confrontation illustrates with dramatic and sobering clarity, why the "culture wars" have become an accelerating cause for concern, rapidly approaching the level of a humanitarian crisis in contemporary American society and throughout the world. As urbane and intellectually sophisticated as their standoff appears, there is good reason to think that be-

\footnotetext{
${ }^{1}$ Far from the metaphysical perspective of a trans-historical and universal connotation, the concept of absoluteness here concerned should be regarded as a "functional" and "heuristic absolute" within the horizon of an inescapable existential finitude, which nevertheless can bring great examples of human dignity.
} 
neath it lies the same psychic death-Terror ${ }^{2}$ that is the generative cause of the various forms of terrorism that characterize our world today and are symptomatic of this historical epoch as an Age of Terror brought on by the still largely subliminal but nonetheless consequential awareness of self-induced species extinction as an increasingly realistic possibility. The concept of "Culture-warfare" implies in fact a sustained and pervasive condition of societal polarization regarding truth claims ("God does/does not exist;" "there is/is not a universal moral law;" "Human activity does/does not play a major role in environmental degradation”) and value priorities ("democracy is overall a more humane form of government than communism" "capitalism is more beneficial overall than socialism") based on the premise that at least in principle a reasonable person should be able to decide that one or the other element of each disjunct is objectively the correct answer. If rational agreement fails in identifying the objectively correct answer, the cause for that failure should be sought in some aspect of subjectivity, which prevents some or all of the participants from recognizing its correctness. As long as either party in a polarized pair of culture-warriors firmly believes that their unwavering conviction of correctness necessarily means that those holding the opposite conviction are incorrect, then there are only two strategic paths available, aggression or conciliation.

At the (mild) risk of caricature, Dawkins, as an enthusiastic and battle-hardened veteran of the contemporary culture wars, argues that atheists are culturally oppressed by totalitarian religion. He therefore pursues the strategy of counter-aggression, contending that religion necessarily involves "bad faith" and as such is guilty of a variety of "war-crimes" including social and moral terrorism and child abuse, both physical and psychic. It is interesting to notice that the same conclusion, that is, the unconditional repudiation of any sort of religious belief and, ultimately of the very possibility of the existence ofGod, was paradoxically reached by Jean Paul Sartre, the most influential figure among existentialists and, along with Dawkins, one of the most radical atheists over the last two centuries. Conceiving the possibility of reality and meaning phenomenologically, that is, only and strictly in relation to human consciousness, Sartre articulates his "rejection of God" as a refusal to make any appeal whatsoever to the absolute otherness of all that is not the self, so that the self alone must bear full responsibility for decisions concerning its humanity and freedom. Collins, on the other hand, pursues the strategy of conciliation, based on the asserted full compatibility of religion and science as long as freedom of individual conscience is unfailingly respected. Following this path, religion and science will be able to work together toward an effective synthesis, a "unified field theory" providing reciprocal enrichment and generativity by means of the complementarity of the two perspectives.

Both of these strategies are, however, fatally flawed and in the end must prove unsustainable. The reason, as noted earlier in the specific case of Dawkins and Collins, is that both strategies are reductionist, and as such inevitably fail to take the full measure of the realities (Reality) with which they have to do.

${ }^{2}$ The notion of death-Terror introduced here and further developed below has been explored in depth by Ernest Becker in works such as The Denial of Death and The Escape from Evil. Becker's work has wide-reaching implications for every aspect of human endeavor, particularly the social sciences, and bears importantly on the issues of the interrelation of subjectivity and objectivity, as well as on the role and limits of quantification as a normative element of social science research and the authority afforded it in guiding cultural development and problem solving.
Each strategy is, of course, independent of the position it is employed to uphold. Dawkins' strategy could be, and obviously frequently is, pursued by religionists, and Collins' by atheists. It is neither the proponent nor the position that is the primary cause of the conflict. It is rather the structure of disjunctive polarity itself, the either/or of reductionism, with its implied assumption of objectivity as an irreducible value to which all other "subjective" forms of value must be subordinated, that instigates a conflict which can neither be won nor pacified, an impossible situation. That which must be opposed is the paralyzing effect of cultural warfare that results in the inability to address real-life challenges and dangers which, left unresolved, place human beings at immediate risk of significant harm.

\section{Traits of Cultural Worldviews}

The reason for this situation of impossibility that is characteristic of the state of "culture-war" is the all-encompassing nature of human cultural reality. Where there is genuine culture, that culture is the enactment of a "worldview", a complex set of ways of understanding and actively engaging the whole sphere of both actualities and possibilities with which human existence is confronted. The concept of Weltanschauung (Hegel, 1910; Kant, 1914) originally emerged in reference to a type of overarching framework generated and eventually co-determined by meaning and value structures articulated within the dynamic context of the cultural history of human societies. Within the context of phenomenology, the notion of worldview became linked to the corresponding notion of "horizon", the indistinct "vanishing point" against which every standpoint and perspective acquires depth of field, so that whatever can become visible is situated and positioned in relation to a horizon. More specifically, the study of the development, variation and decline of the major world cultures in the Western tradition and their social functioning provides an extensive and detailed historical record of a significant analogy of these dynamics to the evolutionary and genetic processes of human biological genome. Random variation, natural selection, replication, mutation, and adaptation of value structures throughout thousands of years of human searching for meaning lend support to the vital role that meanings and values play in assuring human survival. There is a profound truth to the recognition that cultural worldviews, which structure the socio-psychological component of human beings, are as fundamental to and reciprocally influenced by the integrity of individual and social life as are human interactions with their cohorts and with the environment into which they are nested. By definition, a worldview is a comprehensive totality, and as such necessarily exhibits a dynamic which is appropriately termed "totalitarianism". Despite the pervasively negative connotation of "totalitarianism" in general usage, it must be recognized that the very function of a "worldview" and the culture to which it gives rise is to be holistic and, insofar as it is possible, to lend to human experience a sense of equilibrium and integrity, of psychological homeostasis that is, arguably, as genuine a condition of psychic survival as food, drink and sexual reproduction are biological conditions.

The culture wars are symptomatic of an historical state of cultural evolution which credibly threatens the onset of globalized Terror, triggered by the paralysis of the evolutionary adaptation mechanisms exhibited in human beings primarily as the ability to cooperate in the face of a shared danger. Historically, the vital role of this adaptive mechanism is more basic 
than and functionally indifferent to the polarities of atheism and religious belief, objectivity and subjectivity, human and divine, and even to the polarity of life and death. The consequence, then, is that totalitarianism as a characteristic of cultural worldviews has a radically ambivalent field of meaning, stretching out in tension between what might, for want of better terms, be designated "positive" and "negative" poles: positive in that the totalizing dynamic makes possible a meaningful coherence and consistency of experience as a whole; negative in the sense that the totalitarian dynamic is necessarily self-limiting and progressively exclusionary in the process of self-identification ${ }^{3}$.

Every historical identity, individual or communal, depends on both distantiation from and communicative engagement with the Other as such. Hence the polarity characteristic of confrontational opposition is internally related to and inseparable from a second structural dynamic which necessarily complements it. This second dynamic might be identified as the notion of dialogical cooperation which in phenomenological terms is characterized as the "hermeneutic circle". Hermeneutic circularity is the process of dialogical circulation which continually resists the short-circuit of reducing one pole of any relational structure to its oppositional other, and so holds open the possibility of keeping the question that originates dialogue alive by working to enact the conditions, both intellectual and social, necessary in order to render the circulation sustainable.

The identification of totalitarianism as the ambivalent, internal relational dynamic characteristic of worldviews as such carries with it a further consequence: the historically evolved worldviews of major cultural traditions can be incommensurable with one another in important ways. The term "incommensurability" is being used here in the sense of a characteristic of the relationship between rival worldviews at the highest level of generality such that there will always be substantive and significant truth and value claims which can be validly asserted within one worldview that cannot be adequately articulated in terms of their meaning nor objectively adjudicated in regard to their validity in the other world (Kuhn, 1962) .

The difference between Collins and Dawkins can help us clarify the notion of incommensurability. Each takes himself to be making claims for or against religion, and more generically, for a distinctive horizonal worldview on the basis of objective evidence, namely the objectivity of science (Impersonalist) as a trans-historical and universal paradigm of physical laws in Dawkins' perspective, and the objectivity of moral law as ascribable to the universal inviolability of human dignity (Personalist) for Collins. A potential dialogue yielding genuine understanding between them will consistently be short-circuited by their mutual failure to recognize that the objectivity which each preemptively claims is legitimate only within the worldview with which each is personally identified. Since those worldviews are incommensurable with one another, however, the claim to objectivity must be viewed in the context of the other worldview as being not so much incorrect as meaningless, a peculiar kind of "category mistake". Hence it is not possible for one set of arguments to defeat the other on rational objective grounds, because the basic assumptions of the rational objectivity each one claims are sufficiently divergent that they cannot be translated into a shared language, or synthesized into

\footnotetext{
${ }^{3}$ Although the suggestion would require further elaboration, it seems useful to note that the tension between the expensive and exclusionary dynamics of homeostasis correspond broadly to the existential notions of transcendence and finitude, central to the human search for meaning.
}

a common framework of judgment.

\section{The Hero and the Saint}

Personalism and Impersonalism are basic characteristics of incommensurable worldviews and, as such, are genetically related in a cultural sense first suggested by Dawkins himself. Each characteristic is complexly composed of a set of "memes" that are the basic structural components of a worldview as a meaning-structure or interpretive framework. The memes distinctively associated with either characteristic derive from a historical "meme-pool" that can be shared by a variety of specific worldviews, but which are hereditary descendants of a common ancestor. For example, this common ancestor might be understood as an early evolving worldview in which reality is viewed as fundamentally and ultimately impersonal in nature. Impersonalism as the dominant characteristic of a worldview has as its primary implication the notion of reality as a whole in which persons or groups of persons, their interests, hopes, fears, gains or losses, lives and deaths are of no lasting or fundamental significance. "No design, no purpose, no evil, and no good, nothing but blind pitiless indifference” (Dawkins, 1995): Reality in this view is governed by laws of chance and necessity, which as such, are purely indifferent to the weal or woe of persons, whether human or divine. The world of Impersonalism is not created for personal beings, and their fate within it is of no consequence, a matter of indifference except perhaps to themselves. Within such a worldview, the final goal of human experience must be understood as the self-enjoyment of whatever limited integrity, wholeness and qualitative life experience is attainable within the boundaries of its inescapable finitude. This worldview is clearly evident in the inherited meme-pool of the Greco-Roman humanist cultural tradition and in all the primary cultural institutions that arose and flourished within it, for example, the notion of science and scientific knowledge, philosophy and ethics, the conceptions of citizenship and the rule of law among others.

Within the Impersonalist worldview a conception of human personal identity arises that articulates what can be identified as "human excellence (areté)" the best that a person can, with effort, do to fulfill her/his individual destiny (moira) if fate and fortune are properly aligned: that is, a vision of excellence which is properly designated as "heroic". Within a given culture this excellence will be embodied in characters as diverse as Hercules, Theseus, Achilles, bodacious, Orestes, Oedipus, Antigone and Socrates, Plato and Aristotle, Alexander, Aeneas, Caesar, Augustus and Marcus Aurelius. Central to all heroic identity, however, is its standard of self-assessment and its motivating force: honor, or self-esteem. The self alone is the origin and measure of heroic meaning and value. As such, whatever the hero does is done out of a desire not to yield to any external force, no matter how superior to one's own. Benevolence, loyalty, even love and compassion are all possible for the Hero, but only in so far as they are motivated by and directed toward what is one's own: one's own city or people, one's own family, friends, comrades, one's fate in so far as that can be known. The Hero honors the Other, even one's enemy, in so far as the Other is one's own other, the necessary competitor in the game of life, the one who is needed so as to provide the occasion for one to overcome and surpass oneself.

Clearly in these terms Dawkins' position is unrelentingly heroic. Its ascription of normative authority to the objectivity of 
scientific naturalism as the highest realization of rationality (impersonal) reveals him as a sterling specimen of the purest hereditary strains of the heroic meme-pool. He is undoubtedly deeply concerned with the real harms done to human beings in the name of religion, but at bottom, that concern must be understood to be ultimately rooted not in compassionate love, but in the same murderous wrath which motivated Achilles to avenge the death of Patroclus at the hands of Hector. For Dawkins, religionists are the implacable enemies of his own cultural kin. Freedom within the Impersonalist worldview means the inalienable prerogative to avenge one's losses and to fight to the death, to never yield despite the impossibility of victory within the human situation, an impossibility which is never effaced by the benefits of culture enjoyed by some in a fleeting time of peace.

Collins is another matter, however. As a scientist with an unquestionable adherence to the Impersonalist norm of objectivity, his hybridized identity is nevertheless determined by the conflation of both subjective and objective components. He is a passionate proponent of the complementarity and viable synthesis of science and religion as ultimately rooted in the absoluteness of human dignity. Collins' stance expresses then an alternative worldview, affirming by contrast the primacy of personal identity. This cultural frame arises from a Reality that is characterized by love and compassion, within which personal identity is the basic structure for meaning and values. It assumes a fundamental relational dimension, within which the individual identity becomes meaningful only as related to the absolute Other. Freedom proceeds from this relationality, occurring as the open mutuality of personal identity unconditionally exchanged in the circularity of gift-giving and receiving. The total mutuality and reciprocity of this circulation constitutes the quality of responsibility (to the Other as such) which is characteristic of Personalism and as such forms the substance of "conscience"- the knowledge of oneself as existing (only) with the other. In this context, each person owes her/his identity to the Other, who is both human and divine. Personalism is the paradigmatic feature of this worldview that can be metaphorically symbolized by the "Saint" as profiled in the monotheistic scriptural religions, the one who lives for the love of the Other, and all the others.

Faith in God, the all-powerful, beneficent, "One True God" who is the unique source of all life, is the path that the Saint chooses as her or his way of pursuing the search for meaning ${ }^{4}$. Being in question and striving for meaning are indeed the primary conditions of self-consciousness, the traces of the revelation throughout human history of the powerful and dynamic mystery of human existence. Both the heroic and the saintly worldviews are inevitably confronted with the enigmatic relationship of human existence to the whole of reality. Each must recognize and accept the elusive condition of human existence in the face of "Mystery" and its immutable state of being in question as the originating impulse of its vital and self-sus-

\footnotetext{
${ }^{4}$ It is important to recognize that the figure of the Saint as described here is indigenous only to the worldview of Personalism and hence to the religions of scriptural monotheism, Judaism, Christianity and Islam. Therefore, there is no intention here of overlooking other major world religious traditions, such as Hinduism, Buddhism and many others. Rather, this stipulative but non-arbitrary limitation of the type of the Saint to one religious "family" only underscores that like all other major aspects of human culture, the realm of religion is ambivalently shared by the Personalist and Impersonalist worldviews.
}

taining meaning and value, it's "dignity”, in other words. For the Saint, however, rather than conforming to blind necessity, reality is ultimately structured by the implications of a covenant relationship between freedoms based on the reciprocal promises and unconditional trust that a covenant absolutely demands. Abraham's destiny as the "chosen one", singled out from among all the others by virtue of an unexplained design and, by force of the same elusive design, called to the ultimate sacrifice of his own son, exemplifies the saintly archetype and its Reality of totalizing Love, that is, the mutual exchange of "gifts" enacting the relationship through which both parties give and receive their identities.

Like Abraham, Collins chooses the faith in God and embraces the saintly worldview of religion as the articulation of his Personalist worldview with its privileged horizon of the human dimension and the celebration of human dignity, based primarily on its natural, innate, and putatively, universal sense of moral righteousness. Asserting the uniqueness of human experience, he clearly relates its privileged position in all creation to a superior design transcending human finitude that is ultimately responsible for a moral sense of respect for human dignity which is not the product of evolution. Collins, in other words, does not situate the human psyche, or at least the moral dimension of the human psyche, within the dynamics of evolution. For this reason, his scientific perspective does not interfere with his sincere belief and religious commitment, but rather enhances his awareness of Mystery and the greatness of the creationist design, leading him to engage by faith in the recognition of a pre-existing supernatural Creator who triggered life, set the path for its evolution and differentiation, and is constantly present to it. Tellingly, however, the "objective evidence" for the totalizing claims of the Personalist worldview lies in the universality of the normative demands of the moral law, which for Collins does not evolved but is implanted within the human heart by the hand of God directly. In this way, Collins mistakes for "objectivity" a phenomenon which can only be accounted for on the assumption of Personalism as the ultimate character of reality as a whole, a petitio principi isomorphic to the one committed by Dawkins.

Both the Hero and the Saint embody the memetically encoded, ancestral human endeavor of pursuing a meaningful existence recurring throughout the history of human cultural traditions which taken together, it is argued here, constitute a kind of "double-helix" that is the basic structural element of the human cultural genome. Within each worldview, important claims can be clearly articulated with powerful conviction, since both express self-referential universes of meaning built upon an endogenic rationality in terms of which such claims can be fully legitimated. Regrettably for both the aggressive and the conciliatory strategies, however, in the very comprehensive self-referentiality associated with the heroic and saintly traditions lies the core of their incommensurability as polarized frames that altogether resist synthesis and assimilation.

\section{A Commitment to Questioning}

An inevitable choice between or beyond the two paths is thus imposed on the individual who decides affirmatively to face Mystery and bear the weight of an existence devoted to seeking authentic meaning and identity, a choice of a kind that Aristotle classified as belonging to the realm of phronēsis, or "practical wisdom” (Bernstein, 1983; Gadamer \& Fantel, 1975). Unlike techne and episteme, the alternative forms of knowledge identi- 
fied by Aristotle, however, phronēsis requires understanding historically situated human beings, as opposed to permanent universal laws (episteme) or changeable material situations (technē). Phronēsis functions neither as a decision algorithm nor a technical protocol, but rather as deliberative judgment, entirely fallible, but existentially final. With regard to worldviews, phronēsis requires an ongoing process of deliberate judgments by which one identifies oneself through responsible action with one or other worldview, without the implication that such identification is either permanent or progressive. Phronēsis demands a constant shifting back and forth between the two incommensurable worldviews which in their pure form are disposed at the extremes of a spectrum of human possibilities which require mediation between the general and the particular through application and a concrete human situation. The inherent risk and uneasiness of a deliberated decision may be ascribable to any number of factors including the absence of sufficient knowledge, the unpredictability of circumstantial conditions or the unreliability of human agency as well as many more, but in the end, all such imponderable factors derive from the mysterious reality of human finitude. In the end, it must be acknowledged that the problem of "measuring horizons", or discriminating between primordial worldviews by means of phronessis, implies that that ultimately the questions of utmost human importance must remain undecideable, even though concrete decisions must be taken at every step along life's way. This is at least one reading of what Kierkegaard meant by "fear and trembling", in the face of divine mystery, whether that mystery be called God or not. It now becomes clear that for Aristotle, phronesis meant practical wisdom in the sense of making choices that bear not on the production of things, but on the formation of character, or in an even broader sense, personal identity. The choice of a worldview through which to relate oneself to one situation amounts to the existential choice which decides who one will be in that situation. Identity is the responsibility of freedom, not of reason, as Aristotle contended, because Aristotle did not have access to the sweeping historical perspective of cultural evolution.

Both Sisyphus' and Moses's destinies arguably produce promising, "sustainable" experiences of human dignity affirmed at its highest level. The possibility of Sisyphus' happiness, as Albert Camus notes, is in fact concretized through the full lucidity that Sisyphus achieves while endlessly pushing the rock uphill and hence facing the limit of his futile existence (Camus, 1965). His freedom to possess himself and fulfill his own destiny against any adverse fate is as complete as Moses' freedom, commanded by God to flee Egypt leading his people - God's people - out of captivity towards the land of promise which he personally won't reach. Moses the shepherd is called to the destiny of prophet, king and priest, to accept the deferral of the covenant fulfillment while remaining faithful to the promise regardless of contingent misfortunes. Sisyphus the King was called from out of the land of the living into the realm of the dead, and as punishment for his disobedient refusal to pass over, was condemned to futile enslavement to capricious gods whose weight of authority depended on the adamantine necessity of the rock, from which he could never escape but against which he could always rebel through contempt for his fate.

"No algorithm for theory-choice, no systematic decision procedure” (Kuhn, 1962) could support human deliberation between the two disjunctive metaphors of Hero and Saint, since there is no rational basis for discrimination between one worldview as opposed to the other, or for the subordination of one to the other. Rationality operates within a worldview, and the choice between worldviews is a judgment that, by directly confronting Mystery, exceeds the competence of rationality. The historical patterns of cultural evolution clearly reveal a fundamental undecidability, supported by the intuitive recognition first, that the major cultures arising out of each worldview have survived and thrived over centuries, producing ways of life, institutions and artifacts which exhibit the highest levels of enduring excellence; and second, that both individuals and societies past and present clearly do not to fit uniformly within one or the other worldview, but rather exhibit patterns of hybridization which testify to the choice to supplement the strengths of one set of genetic characteristics with those of the other. Even more to the point, however, the very recognition of the Mystery which envelops human existence itself disallows the possibility for any comfort that even theoretically might derive from a claim to possess either the ultimate Truth or Good of reality, since the recognition of mystery makes inauthentic any claim, either by reason or by faith, to possess it securely. Mystery has no truth, has no good; mystery is beyond both, beyond existence itself. Mystery is precisely that which silences the human capacity for language altogether, let alone for affirmation or negation. Even when language miraculously gestures toward Mystery, it can do so only metaphorically, in a way that is fraught with the tension between "same" and "different", between known and unknown, between life and death, and that must always resolve itself again as a question that remains finally undecideable, despite the fact that the finitude of human situation absolutely requires that an authentic decision be made if the dialogue is to begin again anew and sustain itself.

Hence, beyond the dissonance and the irreconcilability of these juxtaposed archetypes, earnestly committing to a meaningful life implies an indefatigable effort towards the affirmation of human dignity, which finds its origin and destiny in freedom. Freedom here does not mean liberty of choice, which is always situational and derivative. To guarantee liberty of choice is the proper goal of human cultural institutions, whether religious, political, economic, social, or psychological. Freedom, however, is beyond situational or circumstantial constraint, beyond conferral or withdrawal. In a sense close to what might traditionally be termed freedom of conscience, it is the basis for human identity and authentic responsibility, in so far as conscience is directed solely toward taking responsibility for who one is, for one's identity, not simply for what one does, for the "how" of choice rather than the "what". Freedom is the source and measure of all value claims, and demands the decision to take authentic responsibility for one's own identity. Bernstein's concept of “Cartesian anxiety” (Bernstein, 1983) conveys the widespread, even familiar feeling of hesitancy and doubtfulness posed by the incommensurability predicament, especially when it goes undiagnosed: Cartesian anxiety arises from the threat of loss of freedom resulting from the necessity to respond to the inevitable choice between the objectivist path, on the one hand, grounded on stable, enduring constraints which offer a certain apparent security for our existence, and the way of relativism, on the other hand, claiming that no fixed points can be discerned in human existence capable of keeping life from floundering in chaotic variability, except for those established by convention or arbitrary stipulation. 


\section{Beyond Undecidability: The Secular Saint}

Culture wars exemplify a stubborn refusal to recognize the reality of genuine undecidability. Consequently, they function as a syndrome that inevitably degenerates into the "eitherlor" dichotomy of Cartesian anxiety driving individuals and groups to push for an unambiguous decision in the name of "truth" or "values". One who deliberately decides uncritically to embrace either of the worldviews which stand behind the two poles indirectly but necessarily asserts the falsifiability of the alternative, although neither verification nor falsification is available as a possibility in such a case. Such resolute errancy fosters a paralyzing incommunicability between the two horizons metaphorically represented by the Hero and the Saint, which fatally inhibits the social cooperation that is necessary condition for the integrity of human dignity and the survival of human societies. The case of opting for one of the two worldviews and in full conscious awareness of entanglement of freedom with Mystery is, in contrast, profoundly different and less injurious to the human dignity because it acknowledges such choices to be situated in the realm of conscience, because the self-identification with one cultural tradition here proceeds on the basis of phronessis toward a practical decision about how to resolve one's personal responsibility for one's own identity in the face of Mystery. The recognition that identifying oneself wholly with one worldview, whether saintly or heroic, rest on personal responsibility for one's own identity rather than on the basis of any form of objectivity is not, therefore, an admission that the basis for such a decision is purely or even primarily subjective. Responsibility encompasses both subjectivity and objectivity comprehensively and exceeds both, recognizing that as a matter of personal conscience responsibility ultimately transgresses the scope of either worldview and as such cannot be held as normative beyond its implications for one's own identity.

The radical irreconcilability of the heroic and saintly worldviews, however, also opens up a third, and it is argued here, preferable option that rests on an authentic openness to the Mystery, but ambitions a value even more elevated than that of absolute respect for the inviolability of human dignity based on freedom of conscience. It ambitions alleviating the misery of human affliction when that dignity is violated. This ambition pursues neither the strategy of counter aggression nor conciliation urged by Dawkins or Collins respectively. Rather it embraces the minimalist principles of refraining wherever possible from doing avoidable harm and of nonviolent resistance to violations of human dignity. Such a strategy might be metaphorically labeled as pursuing the identity of a "Secular Saint". The Secular Saint embodies an equally totalizing commitment to search for meaning simultaneously along both paths, in full conscious acceptance of their incommensurability and of the resulting psychic tension which must inevitably result from attempting "to serve two masters". Such a commitment hopes to gain a richness of value and understanding otherwise inaccessible from within either framework alone. But it is a path which transgresses of the boundaries of reason flouting both the principle of non-contradiction and the principle of sufficient reason. As a result, the path of the Secular Saint can only be pursued on the basis of a hope which rests on an unshakable faith in the inviolable and absolute dignity of human personal existence itself. This paradoxical construct symbolized by the hybridized archetype of the Secular Saint, eventually eschews a polarized stance and refuses to privilege or exclude either the saintly or the heroic identity. The Secular Saint is the person of the late $20^{\text {th }}$ and $21^{\text {st }}$ century, who bears the weight of an historically heightened cultural awareness of the dignity of the human person in the face of the forces of terror that lacerate and paralyze our era in the wake of the sequence of the two World Wars morphing into the Cold War and now the war on terror, exacerbated by the hurtling forward rush of globalization and the imminent threat of species self-extinction due to environmental degradation. Among many possible epigones of secular sainthood, arguably including figures as diverse as Martin Luther King, Gandhi, Mother Teresa, Nelson Mandela and others, the voice of Simone Weil unequivocally expresses this complex identity, rooted in a startling evolutionary adaptive response to the trauma inflicted on the human cultural imagination by the combination of unremitting violence and addictive fixation on consumption of every sort, both heightened to an unprecedented degree by technological saturation. Despite Weil's profoundly intimate love for the for the person of Jesus as portrayed in the Gospel and an underlying faith commitment to the inviolability of human dignity which oriented her whole life, Simone Weil resolutely refused to be baptized a Christian, in keeping with her rejection of any claimed totalization of religious belief-in her case, the Catholic religion in particularinto the realm of secular society, derived as it is ultimately from the memetic heredity of the Hero. The unavoidable violence of institutionalization led, she believed, to the inescapable exclusion of some components of humane religious aspiration and cultural expression which should be respected rather than subordinated to the mechanics of collectivism and totalitarianism. Despite her recognition of the impossibility of reconciliation of the religious and secular dynamics of cultural evolution, Weil resolutely withstood the temptation to betray either her personal faith or the dignity of universal human solidarity.

The metaphor of the Secular Saint refers then to a new awareness of the profundity and scope of human dignity functioning as a finite historical absolute within the sphere of human evolution development from the purely biological level to the psychic level of personal identity. The borderline between these emergent realities is demarcated by the development of linguistic behavior. In a broadly hermeneutic sense, at the level of psychic identity, reality is composed of meanings rather than things or objects, so that hermeneutic understanding operated with the context of ontology of language, rather than a metaphysics of Being. As Hans-Georg Gadamer points out, one consequence of this shift is that, "just as an individual is never simply an individual, because he is always involved with others, so too the closed horizon that is supposed to enclose a culture is an abstraction” (Gadamer, 1975). Being dichotomized in terms of alternative incommensurable worldviews need not imply for human beings the finality of an "irreducible conflict grounded in human plurality”. Incommensurability does not imply incommunicability, but it does require a dialogical commitment to the hermeneutic circularity of inquiry and deliberation in which every arrival demands a return to its original "other". Both the objectivist ambition of cultural traditions as transhistorically (metaphysically) grounded, and the relativist perspectivalism of subjective variations determined by historical contingency disregard a fundamental genomic trait of human existence. At the level psycho-linguistic identity personhood shares in the ontological character which derives from its universal mediation through the center of language: the character of a mediated, dialogical reciprocity governed by the logical 
principle of "Both\And" rather than "Either\Or". Human-being-in-the-world is at one time both historically finite and always "in medias res" (Bernstein, 1983) at the absolute center of the universal circulation of meaning through which all reality passes in the intimate exchange of relational identification. "Cultural pluralism" is a condition of human cultural reality, not a strategy for personal fulfillment or societal flourishing.

\section{Affirming Freedom through Responsibility}

Hence the imperative necessity to assume personal responsibility for one's decisions and choices as one's own, as constitutive of one's human identity, one's absolutely unique response to the question of the "meaning of life" requires that in each instance one confront and overcome "Cartesian anxiety", the "eitherlor" habit of mind with regard to meaning and value structures. Cartesian anxiety, Bernstein underscores, must be "exorcized" as dangerously misleading and downsizing the range of human options to a fearsome, but falsely framed dilemma. Cartesian Anxiety as Bernstein diagnoses seems to be symptommatic of what has been previously referred to here as Terror. "Terror" as used here does not refer to the dichotomy between Self and Other which lie at the center of all human experience and of reality itself, and is a structural condition of both self-consciousness and meaning. Rather it refers to what Ernest Becker has masterfully analyzed as the paradoxical construction of human identity as a "vital lie", vital in the sense that the drive to self-expansive activity at the level of animal instinct necessarily passes over into the psychic level as the will to live and the will to power (and meaning) a lie; in that the denial of death implicit in the life force carries with the guilty awareness not simply only of the biological necessity of physical demise, but also of the pervasive interpenetration of every aspect of human existence and cultural achievement by death as its final limit. For Becker, Terror is the necessary "other" of Joy, and their interrelation in human experience sets up the psychic dynamics of hope and despair. Becker makes clear that all genuine terror is death Terror, and that Terror is altogether different than fear. Fear can be specified and, in a certain sense, quantified. Terror is beyond measure or analysis by cause and effect. Terror, like Joy, is paradoxical in the same way that human existence: it arises entirely out of the finite, historical dynamics of human existence, yet equally and at the same time transcends those dynamics by carrying a significance which is absolute and universal with regard to every possible worldview and culture. In the simplest terms, Terror and Joy are inseparable possibilities within each worldview because life is meaningless apart from death and death is equally meaningless apart from life. This implies that rather than being seen only as the "destroyer of worlds", and the enemy of meaning and value, death must also be acknowledged to be on partner in humanity's parental dyad. This recognition requires in turn a worshipful reverence for human dignity and an unconditional commitment as a "finite absolute" stretching out at a maximal level of tension throughout one's whole existence in order to come to a minimal level of familiarity with the identity of the Secular Saint. Such a person intentionally strives to make himself or herself at home in a condition of permanent dialogical tension between the two polymorphic poles of the mystery of existence, consciously registered as paradox.

But the issue here is not primarily the search for "heightened consciousness" as a path to personal fulfillment or salvation, whatever that might mean. The immediate issue here is less aspirational, yet more urgent, than that. It is, rather, the most basic obligation of responsibility: to respect human dignity by attempting to forestall or contain crimes against humanity by neutralizing to some extent the paralyzing effects of culture warfare on the human imagination functioning through adaptive cooperation with others to stem violence and curtail the infliction of avoidable harm and misery on individuals, cultures, the environment and species, including our own. Paradox, rooted as it is in the structure of freedom itself, is irremediably ambiguous. As a consequence, even while culture warfare progressively paralyzes us, the tension underlying it might prove itself effective in allowing an uninterrupted circulation of meanings and values on the basis of which a "stable pairing" of the subjective and objective exigencies of experience, yield a psychic culture of sustainability as the prerequisite for a public culture that is both capable and committed to the goal of living familiarly at peace with the paradox which is human existence and the source of its dignity.

A final analogy might help to clarify this unceasing metaphorical exchange: starting from a purely phenomenological perspective, Sartre describes the human conscious experience of the world as a constant exchange between the dynamic of objectivity and the dynamic of subjectivity, corresponding to the two poles of object awareness and self-awareness, where each pole is meaningless if excluded from this interchange. Relationality is once more highlighted as the essential condition for meaningful existential experience, although characterized as an unstable flux between the two figurative extremes, where "instability" denotes a dynamic variability which is contextual, that is dependent upon the "intentionality structure" framework or worldview within which the exchange takes place. This example interestingly recalls some characteristic traits of quantum mechanics, such as its fundamental relationality seen in the complementary and uncertainty principles, which together imply the same property of incommensurability which is here attributed to the Impersonalist and Personalist worldviews.

It is "Limited, finite", but also "changing, fluid" (Gadamer, 1975). Gadamer's definition of a horizon essentially frames the intrinsic ambiguity not simply of human existence and experience but also of the reality which is the mysterious rather of that existence. The coexistence of the two notions of Quantity and Quality and their related parameters and values as defined along this analysis within the Impersonalist and Personalist worldviews is then finally assessed as indispensable, despite its inevitable entanglement in a dynamic of continuous, ambivalent mutual co-determination. It is the relation which is ambivalent and as such the elements of the relation participate in that ambiguity as an existential absolute. This is basis of the historically peculiar predicament in which contemporary human beings find themselves situated. Following in the wake of the still contentious appropriation of Darwinian evolutionary theory and genetic understanding, the reality of cultural genetic evolution is gradually becoming more apparent. At the same time, the human futility of totalitarian worldviews unchastened by the correlative realization of the finitude of very truth and value claim without exception weighs upon us ever more disturbingly. In this situation, the suggestion put forward here is that perhaps the greatest gift offered by an unqualified affirmation of human dignity as the origin and final referent of every such claim of truth and value might reside in the realization that authentic hope is possible only in the face of Mystery and at the price of 
taking upon ourselves the paradoxical character of human existence which excludes defeat even as it does victory. To be sure this is a "humiliated hope", a hope that, even as it would soar, finds itself tethered to the earth so that its feet must always remain on the ground. But to ask, "Is this enough?" brings us back again to the single conclusion toward which we have all along been underway here. There is always only one answer to the question, "Who is to say?" and that answer is: oneself, the one claims the dignity to be allowed to say "I" and saying so becomes responsible for the identity which the "I" impossibly promises. No objectivity has the authority to lift the burden of responsible freedom; no subjectivity has the stature to bear freedom's dignity.

\section{REFERENCES}

Bernstein, R. J. (1983). Beyond objectivism and relativism: Science, hermeneutics, and praxis. Chicago: University of Pennsylvania Press.
Camus, A. (1955). The myth of Sisyphus. Hamish Hamilton.

Collins, F. S. (2006). The language of God: A scientists presents evidence for beliefs. Simon and Schuster.

Dawkins, R. (1995). River out of Eden: A Darwinian view of Life. London: Weidenfeld and Nicholson.

Dawkins, R. (2006). The God Delusion. Boston: Houghton Mifflin.

Gadamer, H. G. (1975). Truth and Method. New York: Seabury Press.

Gadamer, H. G., \& Fantel, H. (1975). Problems of Historical Consciousness. Graduate Faculty Philosophy Journal, 5, pp. 8-52.

Giordano, J., Benedikter, R., \& Kohls, N. B. (2012). Neuroscience and the importance of a Neurobioethics: A reflection upon Fritz Jahr. In A. Muzur, \& H.-M. Sass (Eds.), Fritz Jahr and the Foundations of Integrative Bioethics. Münster; Berlin: LIT Verlag.

Hegel, G. W. F. (1812-1816). Wissenschaft der Logik. Schrag, Nürnberg.

Hegel, G. W. F. (1910). The phenomenology of mind. London: Schwann Sonnescheim \& Co, The Mac Millan Company; New York.

Kant, I. (1914). Critique of judgment. London: Mac Millan \& Co.

Kuhn, T. S. (1962). The structure of scientific revolution. Chicago: University of Chicago Press. 